\title{
The Khuff Impact on Unayzah Seismic Response: Umm Jurf Field
}

\author{
Salem Gulaiyel Aljuhani (Texas A\&M University at Qatar \\ $<$ salem.aljuhani@qatar.tamu.edu>)
}

The combined effects of variations in thickness and impedance in the Khuff Formation are significant and are sources of noise in the seismic image of the Unayzah Formation in the Umm Jurf Field. They obscure important reservoir signals and degrade the accuracy of the depth and thickness maps. The influence of these variations is readily seen on seismic time and horizon slices.

The upper part of the Khuff is mainly a high-impedance carbonate unit divided by a thin calcareous shale layer. The top Khuff amplitude represents a sharp contrast with the lowimpedance Sudair shale, but lateral variations in thickness and acoustic properties of the shale layer below the top Khuff introduced significant variations in the composite seismic response of the top Khuff, which in turn affected the subsequent signals.

The basal part of the Khuff includes stable and uniform anhydrite layer and stack of carbonates and siliciclastic layers. There are very distinctive channel networks in the basal Khuff with a very strong impedance contrast, which makes these channels prominent features on the seismic data. Overprints from the Khuff channels into Unayzah Formation are evident on seismic slices that were cut through the reservoir. The overprint problem is a limiting factor on the interpretation of the seismic data in Umm Jurf Field.

The trend of variation oscillates in the basal Khuff because of the interaction between two depositional mechanisms of almost perpendicular strikes. The clastic sediments that were deposited during sea-level drops at the base Khuff cut into the carbonate in their movement towards the east and southeast. This process leaves isolated patches of carbonates and siliciclastics, producing lateral lithofacies heterogeneity. These variations are a significant cause of the geological noise in the reservoir interval. 